Journal Article: Antunez, M. (2007). Occupational Hearing Loss in Agricultural Settings. Journal of Agricultural \& Food Information, 7(4), 57-62. ISSN: 1049-6505 Haworth (Taylor and Francis)

DOI: 10.1300/J108v07n04_06

KEYWORDS. Hearing loss | occupational hearing loss | hearing loss prevention | labor safety, agricultural workers | farmers | agriculture

\title{
Occupational Hearing Loss in Agricultural Settings
}

\section{Marilia Antunez}

\begin{abstract}
Most of the materials on hearing loss due to noise in the agricultural industry are training and research-oriented materials in the form of brochures, manuals, and journal articles, published by academic presses, government associations, and professional organizations, respectively. Few books are entirely devoted to the topic of hearing loss in agricultural settings. Recently, many occupational and safety Web sites have been adding information and links to publications dealing with hearing loss in the agricultural industry. This Webliography represents the author's best efforts to briefly describe some authoritative Web sites with information targeted to individuals interested in farm occupational hearing loss.
\end{abstract}

\section{INTRODUCTION}

Although most of us do not associate noise with the agricultural in dustry, it is a relatively common physical agent in an agricultural work setting. Research suggests that farmers who are exposed to the pro longed or excessive noise present in running tractors, machinery, tools, and livestock may be at a high risk of developing hearing loss. Hearing loss due to noise in the agricultural industry has only recently attracted the attention of researchers, particularly those in the occupational research arena.

Currently, employers in the agricultural industry are not required to comply with the U.S. Department of Labor Occupational Safety and Health Administration's (OSHA) noise standards. These standards require the implementation of hearing loss prevention 
programs. To meet this need, several states have adopted OSHA-approved plans that include occupational safety and health programs. Some of these programs address the importance of farm occupational hearing loss (U.S. Dept. of Labor. OSHA, 2006).

This Webliography presents some useful and reliable sites providing information and resources related to farm occupational hearing loss. Literature on hearing loss in the agricultural industry is in its infancy. This is evident by the limited number of publications, including information found on Web sites, dealing exclusively with farm occupational hearing loss. As a result, most of the selected Web sites focus mainly on related topics such as labor safety and hearing loss. The selected sites provide educational, professional, and research resources and information for individuals interested in the issues of hearing impairment in the agricultural industry. In addition, the sites represent a combination of not-for-profit, federal, and academic organizations, as well as other interested national organizations, mainly from the United States. A Web site dealing primarily with occupational hearing loss in the agricultural sector is listed first. Web sites were selected based on the author's own assessment of quality and on recommendations from audiologists. Most sites were found by using the Internet search engines, Google and Dogpile.

\title{
OCCUPATIONAL HEARING LOSS IN RURAL SETTINGS
}

This Web site deals directly with the agricultural worker, working conditions, protection against hearing loss and related issues:

\section{Farm Noise and Hearing Project http://www.farmnoise.on.net/}

This is the Web site of a privately funded network of farmers and health professionals, including speech-language pathologists, audiologists, community nurses, and hearing advisers, who take part in hearing conservation activities, such as health fairs, in rural communities throughout South Australia.

\section{LABOR SAFETY}

\author{
National Agricultural Safety Database (NASD) \\ http://www.cdc.gov/nasd/index.html
}


This is an information-clearing house for agricultural safety and health information, including hearing loss materials. It provides fact sheets, streaming video, training materials, news releases, journal articles, posters, and public service announcement scripts. Some foreign-language materials are also provided. NASD includes materials from many government and academic sources, including the National Institute of Occupational Safety and Health (NIOSH).

\section{The Occupational Safety and Health Administration http://www.osha.gov/index.html}

OSHA is a federal agency under the U.S. Department of Labor that establishes protective labor standards and enforces these standards in conjunction with other agencies. Their Web site provides a wealth of resources including laws, regulations, interpretations, training materials, statistics, and compliance assistance on occupational safety and health topics. The "Noise and Hearing Conservation" pages include standards and training materials such as interactive Web-based training tools on hearing loss prevention.

\section{The National Institute for Occupational Safety and Health http://www.cdc.gov/niosh/homepage.html}

NIOSH is part of the U.S. Centers for Disease Control and Prevention ( CDC) and is the federal agency responsible for research, surveillance, and making recommendations for the prevention of work-related disease and injury. It has several hearing loss prevention programs:

\section{Community Partners for Healthy Farming Intervention Research http://www.cdc.gov/niosh/pgms/commpart/}

In this NIOSH-funded program, national, local, state, and regional partners work to implement and evaluate existing or new interventions 60 JOURNAL OF AGRICULTURAL \& FOOD INFORMATION

for preventing work-related injuries, illness, and death in agriculture. The site provides links to its several projects related to farm safety.

\section{Farm Family Health and Hazard Surveillance (FFHHS) http://www2a.cdc.gov/ffhhs/}

This NIOSH program involves cooperative agreements with education and health agencies in six states that focus on identifying health risks to agricultural workers and their families. Its search engine provides reports, standardized surveys, hazard observation, and medical screening data, statistics and data sets, questionnaires, and 
codebooks.

\section{Noise and Hearing Loss Prevention http://www.cdc.gov/niosh/topics/noise/default.html}

This is the NIOSH Topic Page on noise and hearing loss prevention. This comprehensive and visually appealing site provides access to many $\mathrm{NIOSH}$ publications for individuals interested in hearing loss prevention. Training and educational materials such as fact sheets, an audible noise meter, charts, graphs, an online hearing test, a Power Tools Database, downloadable brochures, and PowerPoint files, and other useful hearing protection materials are easily accessible. The site also contains the database, Hearing Protector Device Compendium, which identifies protectors by type, manufacturer, features, desired Noise Reduction Ratings (NRR), and other product information.

\section{HEARING LOSS}

These Web sites focus on communicative disorders such as hearing loss and provide access to some documents dealing with noise exposure in agricultural settings:

\section{National Hearing Conservation Association (NHCA) http://www.hearingconservation.org/index.htmI}

$\mathrm{NHCA}$, an organization whose mission is to prevent hearing loss due to noise and other environmental factors, provides educational opportunities for professionals involved with hearing loss prevention through conferences, publications, news, and other networking opportunities. The site offers a comprehensive source of resources on hearing conservation including bibliographies, regulatory and training materials, and related Web sites.

\section{National Institute on Deafness and Other Communication Disorders (NIDCD) www.nidcd.nih.gov}

This clearinghouse provides information and resources for health professionals, patients, industry, and the public on human communication disorders, including hearing loss. NIDCD is one of the Institutes that comprise the National Institutes of Health $(\mathrm{NIH})$. Its "Wise Ears" campaign is a collaboration of several other organizations whose goal is to prevent noise-induced hearing loss. The site offers statistical and hearing loss prevention information for the general public, the media, and Spanish-language speakers, as well as a toll-free number to contact a health information specialist for 
questions.

National Institute for Farm Safety, Inc. (NIFS) http://www.ag.ohiostate.edu/\%7Eagsafety/NFIS/nfis.htm

The NIFS Web site provides professional development opportunities for professionals in the agricultural industry. Its Rural Occupational Health Committee is responsible for identifying and classifying occupational health hazards faced by the agricultural community and encourages the development and dissemination of appropriate educational materials to help prevent and reduce occupational illnesses in agriculture.

\section{Noise Pollution Clearinghouse (NPC)} http://www.nonoise.org/

This site represents a national nonprofit organization and consists of a search engine that provides access to journal articles, books, and relevant Web sites. In addition, users have access to news, information on noise legislation, and other tools for activists and trainers that address the issue of noise in the community and the workplace.

\section{ASSOCIATIONS AND ORGANIZATIONS}

\section{American Society of Agricultural and Biological Engineers (ASABE) http://www.asabe.org/}

This is a professional and technical organization for engineers and non-engineers. The ASABE Technical Library database provides access to the Organization's scholarly publications dealing with the knowledge and application of engineering in agriculture.

\section{American Speech-Language-Hearing Association (ASHA) http://www.asha.org/default.htm}

This is the official Web site of the professional and accrediting body for audiologists, speech-language pathologists, and hearing and speech scientists who provide hearing conservations, and diagnostic, rehabilitative, and consultative services and conduct research for individuals who are at risk for or have hearing disorders. ASHA members 
have access to its publications and the public can access hearing conservation materials.

The National Safety Council (NSC) http://www.nsc.org/index.htm

The Web site for this large nonprofit, nongovernmental, international organization provides access to educational and training resources as well as publications on safety and health information, including hearing loss in agriculture. NSC members have access to research assistance by professional librarians.

\section{REFERENCE}

U.S. Department of Labor. Occupational Safety and Health Administration. Agricultural Operations Page. <http://www.osha.gov/SLTC/agriculturaloperations/index.html> (11 April 2006). 